\title{
Aqueous extract of Rabdosia rubescens leaves: forming nanoparticles, targeting P-selectin, and inhibiting thrombosis
}

This article was published in the following Dove Press journal:

International Journal of Nanomedicine

4 November 2015

Number of times this article has been viewed

\author{
Yuji Wang' \\ Jingcheng Tang' \\ Haimei Zhu' \\ Xueyun Jiang' \\ Jiawang Liu' \\ Wenyun $\mathrm{Xu}^{\prime}$ \\ Haiping Ma' \\ Qiqi Feng' \\ Jianhui Wu' \\ Ming Zhao ${ }^{1,2}$ \\ Shiqi Peng' \\ 'Beijing Area Major Laboratory of \\ Peptide and Small Molecular Drugs, \\ Engineering Research Center of \\ Endogenous Prophylactic of Ministry \\ of Education of China, Beijing \\ Laboratory of Biomedical Materials, \\ College of Pharmaceutical Sciences, \\ Capital Medical University, Beijing, \\ People's Republic of China; ${ }^{2}$ Faculty of \\ Biomedical Science and Environmental \\ Biology, Kaohsiung Medical University, \\ Kaohsiung, Taiwan
}

Correspondence: Ming Zhao; Shiqi Peng Beijing Area Major Laboratory of Peptide and Small Molecular Drugs, Engineering Research Center of Endogenous Prophylactic of Ministry of Education of China, Beijing Laboratory of Biomedical Materials, College of Pharmaceutical Sciences, Capital Medical University, No. I0, Xitoutiao, You An Men, Beijing 100069, People's Republic of China Email mingzhao@bjmu.edu.cn; sqpeng@bjmu.edu.cn

\begin{abstract}
The hot water extract of Rabdosia rubescens was traditionally used as an antithrombotic medicine. To explore its antithrombotic utility and mechanism, we carried out a series of in vitro and in vivo assays in this study. In vitro platelet aggregation assay showed that the half maximal inhibitory concentration values of aqueous extract of $R$. rubescens leaves (AERL) inhibiting platelet aggregation induced by thrombin, arachidonic acid, adenosine diphosphate, and plateletactivating factor ranged from $0.12 \mathrm{mg} / \mathrm{mL}$ to $1.43 \mathrm{mg} / \mathrm{mL}$. The minimal effective oral dose of AERL inhibiting the rats from forming thrombus was $25 \mathrm{mg} / \mathrm{kg}$. Both in vitro and in vivo actions were correlated with AERL concentration-dependently inhibiting sP-selectin release. In water, AERL formed nanoparticles, and their size depended on the concentration. Docking the five nucleotides, 21 phenolic acids, and four diterpenoids identified by high-performance liquid chromatography-photodiode array detector/(-)electrospray ionization-tandem mass spectrometry analysis into the active site of $\mathrm{P}$-selectin, rosmarinic acid was predicted to be the antithrombotic ingredient of AERL. In flow cytometry analysis, $1 \mu \mathrm{M}$ of rosmarinic acid effectively inhibited sPselectin release in arachidonic acid-activated platelets. In a rat model, $5 \mathrm{mg} / \mathrm{kg}$ of oral rosmarinic acid effectively inhibited thrombosis.
\end{abstract}

Keywords: $R$. rubescens, sP-selectin, antithrombotic ingredient

\section{Introduction}

Plant materials have long been used as traditional medicines to treat various ailments and diseases. Traditional medicines attract much interest due to their ability to inhibit inflammation, platelet aggregation, thrombosis, ischemia of myocardium, cancer, etc. ${ }^{1-6}$ Rabdosia rubescens leaves (also named donglingcao) is a native herb to the Yellow River, Yangtze River, Taihang Mountains, and Mount Wangwu of North China, People's Republic of China. The hot water extract of $R$. rubescens leaves was traditionally used to treat stomachache, pharyngitis, cough, thrombosis, etc, ${ }^{7}$ but most of the research about $R$. rubescens leaves has focused on the nonaqueous extracts. ${ }^{8-14}$ Thus, the ingredients of the aqueous extract need to be addressed. Recently, we identified five nucleotides, four diterpenoids, and 21 phenolic acids from the aqueous extract of $R$. rubescens leaves (AERL) with high-performance liquid chromatography (HPLC)-photodiode array detector (PDA)/(-)electrospray ionization-tandem mass spectrometry ((-)ESI-MS/MS) and disclosed its in vivo anti-inflammatory and analgesic actions on mouse models. ${ }^{15}$ However, the effective ingredients and molecular targets remain unknown.

P-selectin, a glycoprotein receptor as an essential effector expressed on activated human platelets, is stored in the $\alpha$-granules of the platelets in physiological conditions. In pathological conditions, however, $\mathrm{P}$-selectin is transferred from the $\alpha$-granule to the surface membrane of platelets and converted into the blood circulation as soluble 
P-selectin (sP-selectin). The increase of sP-selectin levels in blood is one of the downstream events of in vivo platelet aggregation and thrombosis, and, consequently, the downregulation of $\mathrm{sP}$-selectin is considered a possible target of both anti-inflammatory and antithrombotic agents. ${ }^{16-21}$ In this study, we hypothesized that AERL is capable of inhibiting the formation of thrombus and we investigated the in vitro antiplatelet aggregation, in vivo antithrombotic activity, in vitro inhibition of P-selectin, and nanofeatures of AERL. In addition, we docked the five nucleotides, four diterpenoids, and 21 phenolic acids of AERL into the active site of P-selectin to explore the antithrombotic ingredient.

\section{Materials and methods Preparing AERL}

Dry $R$. rubescens leaves (from Jiyuan, People's Republic of China; Dr Jingcheng Tang was responsible for the proper identification of $R$. rubescens and $R$. rubescens leaves) were ground and sifted through a $0.45 \mathrm{~mm}$ sieve in order to get fine powder. In a $50 \mathrm{~mL}$ Erlenmeyer flask, $0.5 \mathrm{~g}$ of powder was suspended in $10 \mathrm{~mL}$ of redistilled water. The suspension was stirred by using the same procedure for soaking tea, ie, stirring the suspension at $80^{\circ} \mathrm{C}$ for 30 minutes, then centrifuged (10 minutes, $2,000 \times g$ ), filtered through a $0.45 \mu \mathrm{m}$ microporous membrane, and evaporated under reduced pressure $\left(40^{\circ} \mathrm{C}\right)$ to get $0.15 \mathrm{~g}$ of AERL as light yellow solids.

\section{HPLC-PDA analysis}

The HPLC-PDA analysis was performed on a Waters 2695 HPLC system with a Waters 2996 PDA. The HPLC column was a Kromasil $C_{18}$ (Dikma, Lake Forest, CA, USA) reversed-phase column $(5 \mu \mathrm{m}, 250 \mathrm{~mm} \times 4.6 \mathrm{~mm})$ protected by a guard column of the same material $(5 \mu \mathrm{m}, 10 \mathrm{~mm} \times 4.6 \mathrm{~mm})$. The column thermostat was maintained at $40^{\circ} \mathrm{C}$. Onto the column, $50 \mu \mathrm{L}$ of sample solution was injected for analysis. The mobile phase consisted of solvent A (spectroscopically pure acetonitrile; Beijing Chemical Works, Beijing, People's Republic of China), solvent B (0.05\% [v/v] acetic acid; Beijing Chemical Works), and solvent $\mathrm{C}(0.5 \%[\mathrm{v} / \mathrm{v}]$ acetic acid in water; Beijing Chemical Works). The gradient elution program was described previously. ${ }^{15}$ The flow rate of the mobile phase was $0.3 \mathrm{~mL} / \mathrm{min}$. After each run, the column was washed with acetonitrile and equilibrated to initial conditions for 15 minutes. UV absorption 3D spectra were recorded online. The PDA detector was set to a scanning range from $200 \mathrm{~nm}$ to $400 \mathrm{~nm}$.

\section{Animals}

Male Wistar rats were purchased from the Laboratory Animal Center of Capital Medical University (Beijing,
People's Republic of China). The described assessments were based on a protocol (number: AEEI-2014-050) reviewed and approved by the Ethics Committee of Capital Medical University. The rats (weighing 250-300 g) were housed in polypropylene cages at $22^{\circ} \mathrm{C} \pm 2{ }^{\circ} \mathrm{C}$ and relative humidity of $60 \%-70 \%$, with an automatically controlled 12/12-hour light/dark cycle, and provided with the standard pellet diet and drinking water in plastic bottles. All assays were conducted between 9 am and $4 \mathrm{pm}$. An overnight fast was imposed before assays.

\section{In vitro antiplatelet aggregation assay}

A two-channel Chronolog aggregometer was used to evaluate platelet aggregation. The platelet count was determined with an H-10 cell counter. Pig blood containing 3.8\% sodium citrate (1:9 v/v, citrate:blood; purchased from the Laboratory Animal Center of Capital Medical University) was centrifuged at $100 \times g$ for 10 minutes, and the platelet-rich plasma (PRP) was collected. The remaining blood was centrifuged for an additional 10 minutes at $1,500 \times g$ to prepare platelet-poor plasma. The final platelet count of the PRP was adjusted to $2 \times 10^{8}$ platelets $/ \mathrm{mL}$ with autologous platelet-poor plasma. Into an optical aggregometry testing tube, $0.5 \mathrm{~mL}$ of the adjusted plasma sample and $5 \mu \mathrm{L}$ of normal saline (NS), $5 \mu \mathrm{L}$ of the solution of aspirin (Sigma-Aldrich Co., St Louis, MO, USA) in NS (positive control, in a series of final concentrations of $1,0.1,0.01,0.001$, and $0.0001 \mathrm{mg} / \mathrm{mL}$ ), or $5 \mu \mathrm{L}$ of the solution of AERL in NS (in a series of final concentrations of $100,10,1,0.1,0.01$, and $0.001 \mathrm{mg} / \mathrm{mL}$ ) was added. After adjustment of the baseline, $5 \mu \mathrm{L}$ of the solution of platelet-activating factor (PAF) (Sigma-Aldrich Co.) (final concentration $0.1 \mu \mathrm{M}$, prepared with NS), $5 \mu \mathrm{L}$ of the solution of adenosine diphosphate (ADP) (Sigma-Aldrich Co.) (final concentration $10 \mu \mathrm{M}$, prepared with NS), $5 \mu \mathrm{L}$ of the solution of arachidonic acid (AA) (Sigma-Aldrich Co.) (final concentration $350 \mu \mathrm{M}$, prepared with $1 \mathrm{M}$ sodium carbonate), or $50 \mu \mathrm{L}$ of the solution of thrombin (TH) (Sigma-Aldrich Co.) (final concentration $0.1 \mathrm{U} / \mathrm{mL}$, prepared with $\mathrm{NS}$ ) was added, and aggregation was recorded at $37^{\circ} \mathrm{C}$ for 5 minutes. The effect of AERL on PAF-, ADP-, AA-, or TH-induced platelet aggregation was observed in sextuple tubes. The maximum platelet aggregation $\left(\mathrm{A}_{\mathrm{m}}\right)$ of NS, aspirin in NS, or AERL in NS was represented by the peak height of the aggregation curve (equal to the maximum light transmission). The inhibition rate was calculated according to the following formula:

$$
\text { Inhibition } \%=\frac{\mathrm{A}_{\mathrm{m}} \text { of } \mathrm{NS}-\mathrm{A}_{\mathrm{m}} \text { of AERL }}{\mathrm{A}_{\mathrm{m}} \text { of } \mathrm{NS}} \times 100 \%
$$


$\mathrm{A}_{\mathrm{m}} \%$ of NS, the values of platelet aggregation induced by PAF, ADP, AA, and TH without AERL, were $53.03 \% \pm 1.82 \%$, $51.20 \% \pm 3.44 \%, 49.94 \% \pm 2.67 \%$, and $62.15 \% \pm 3.26 \%$, respectively. The concentration vs inhibition rate curve was plotted to determine the half maximal inhibitory concentration $\left(\mathrm{IC}_{50}\right)$ values with the statistical program GWBASIC. EXE (GWBASIC is a dialect of the BASIC programming language developed by Microsoft Corporation [Redmond, WA, USA] from BASICA).

\section{In vivo antithrombotic assay}

Male Wistar rats weighing 250-300 g were used in this assay. Aspirin (positive control) and AERL were dissolved in NS before administration and kept in an ice bath. Thirty minutes after the oral administration of $3 \mathrm{~mL} / \mathrm{kg}$ of NS (negative control), $3 \mathrm{~mL} / \mathrm{kg}$ of aspirin in NS (positive control, $3 \mathrm{mg} / \mathrm{kg}$ and $30 \mathrm{mg} / \mathrm{kg}$ doses), $3 \mathrm{~mL} / \mathrm{kg}$ of AERL in NS $(50 \mathrm{mg} / \mathrm{kg}$, $25 \mathrm{mg} / \mathrm{kg}$, and $5 \mathrm{mg} / \mathrm{kg}$ doses), or $3 \mathrm{~mL} / \mathrm{kg}$ of the antithrombotic ingredient in NS $(25 \mathrm{mg} / \mathrm{kg}, 5 \mathrm{mg} / \mathrm{kg}$, and $0.5 \mathrm{mg} / \mathrm{kg}$ doses), the rats were anesthetized with pentobarbital sodium (Beijing Pharmaceutical Works) $(80.0 \mathrm{mg} / \mathrm{kg}$, intraperitoneal) and the right carotid artery and left jugular vein were separated. A weighted $6 \mathrm{~cm}$ thread was inserted into the middle of a polyethylene tube which was filled with heparin sodium ( $50 \mathrm{IU} / \mathrm{mL}$, in NS). One end of the polyethylene tube was inserted into the left jugular vein. From the other end of the polyethylene tube, heparin sodium was injected as anticoagulant, and this end was inserted into the right carotid artery. Blood was allowed to flow from the right carotid artery to the left jugular vein through the polyethylene tube for 15 minutes. The thread was retrieved to obtain the thrombus weight. After operation, the treated rats were euthanized immediately by exsanguination from the right carotid artery under pentobarbital sodium anesthesia.

\section{sP-selectin determination}

sP-selectin levels were measured on citrated rat blood samples by enzyme-linked immunosorbent assay (ELISA) according to the manufacturer's instructions with a rat P-selectin ELISA kit (Cusabio Biotech Co, Wuhan, People's Republic of China). Rat blood was collected in a 3.8\% sodium citrate solution $(1: 9 \mathrm{v} / \mathrm{v})$ and immediately centrifuged at $160 \times g$ for 15 minutes to collect PRP. To prepare the PRP sample, $5 \mathrm{~mL}$ of the diluent (from the kit) was added to $5 \mathrm{~mL}$ of PRP. To prepare $R$. rubescens solutions $(0.5 \mathrm{mg} / \mathrm{mL}, 5.0 \mathrm{mg} / \mathrm{mL}$, and $50.0 \mathrm{mg} / \mathrm{mL})$, AERL was dissolved in NS. For the test samples, to a $960 \mu \mathrm{L}$ PRP sample, $20 \mu \mathrm{L}$ of AERL in NS was added, followed by incubation at $37^{\circ} \mathrm{C}$ for 5 minutes, to which $20 \mu \mathrm{L}$ of AA in $\mathrm{NS}(0.15 \mathrm{mg} / \mathrm{mL})$ was added, followed by incubation at $37^{\circ} \mathrm{C}$ for 3 minutes. For the blank control sample, to a $960 \mu \mathrm{L}$ PRP sample, $20 \mu \mathrm{L}$ of NS was added, followed by incubation at $37^{\circ} \mathrm{C}$ for 5 minutes, after which $20 \mu \mathrm{L}$ of AA in NS $(0.15 \mathrm{mg} / \mathrm{mL})$ was added, followed by incubation at $37^{\circ} \mathrm{C}$ for another 3 minutes. To the test wells and the control wells of a 96-well plate coated with the enzyme, 100 $\mu \mathrm{L}$ of AERL-treated PRP sample and $100 \mu \mathrm{L}$ of NS-treated PRP sample were added, respectively. After incubation at $37^{\circ} \mathrm{C}$ for 120 minutes and removal of the solvent, $100 \mu \mathrm{L}$ of the biotin labeled antibody (from the kit) was added to each well. The plate was incubated at $37^{\circ} \mathrm{C}$ for 60 minutes, and the solvent was removed. After washing with washing solution (from the kit) three times, $100 \mu \mathrm{L}$ of horseradish peroxidase labeled avidin (from the kit) was added to each well, the plate was incubated at $37^{\circ} \mathrm{C}$ for another 60 minutes, and the solvent was removed again. After washing with washing solution (from the kit) five times, $90 \mu \mathrm{L}$ of the substrate (from the kit) was added to each well, gently mixed, and protected from light for 20 minutes at $37^{\circ} \mathrm{C}$ for coloration. To each well, $50 \mu \mathrm{L}$ of the stop solution (from the kit) was added to stop coloration. The optical density value of each well was recorded at $450 \mathrm{~nm}$ and the sP-selectin level was determined according to the standard samples (from the kit).22

\section{Flow cytometry assay}

Rat blood was collected in an aqueous solution of $3.8 \%$ sodium citrate $(1: 9 \mathrm{v} / \mathrm{v})$ and immediately centrifuged at $160 \times \mathrm{g}$ for 15 minutes to get PRP. To $500 \mu \mathrm{L}$ of PRP, $10 \mu \mathrm{L}$ of the antithrombotic ingredient in NS (final concentration, $0.1 \mu \mathrm{M}$ ) was added, and the mixture was incubated at $37^{\circ} \mathrm{C}$ for 30 minutes, to which $10 \mu \mathrm{L}$ of AA in NS $(0.15 \mathrm{mg} / \mathrm{mL})$ was added. The system was incubated at $37^{\circ} \mathrm{C}$ for 5 minutes and centrifuged at $500 \times g$ for 10 minutes to precipitate the platelets. The precipitated platelets were then stained with PE-anti-CD62P (Shanghai XingYou Biological Technology Co., Ltd, Shanghai, People's Republic of China) for 20 minutes. PE fluorescence, for gated platelet populations, was analyzed for $\sim 30,000$ events (counts) per sample aliquot and fluorescence data were recorded accordingly. The level of platelet activation was assessed by the fluorescence height of P-selectin.

\section{Transmission electron microscopy images} The characterization of the nanoimage of the lyophilized solids of AERL in water was identified by transmission electron microscopy (TEM) (JSM-6360 LV; JEOL, Tokyo, Japan). The solution of AERL in ultrapure water $(1.0,0.5,0.25$, and $0.12 \mathrm{mg} / \mathrm{mL}$ ) was dripped onto a carbon-coated Formvar copper grid and then a drop of anhydrous ethanol was added in order to assist the removal of water. The grid was dried thoroughly in air, and the TEM image was tested at an $80 \mathrm{kV}$ electron beam accelerating voltage. The nanoimages were 
recorded on an imaging plate (Gatan Bioscan camera model 1792) with $20 \mathrm{eV}$ energy windows at 6,000-400,000×. The TEM image was obtained from counting over 100 species in a randomly selected region. The images were digitally enlarged. All determinations were carried out in triplicate grids.

\section{Atomic force microscopy images}

Atomic force microscopy (AFM) images were obtained using the contact mode on a Nanoscope 3D AFM (Veeco Instruments, Inc., Plainview, NY, USA) under ambient conditions. Samples of AERL in rat plasma $(0.5 \mathrm{mg} / \mathrm{mL})$ and rat plasma alone were used for recording the images.

\section{Molecular docking}

In the molecular docking, the structure of P-selectin was treated as rigid and prepared by AutoDockTools 1.5, ie, merging nonpolar hydrogens and assigning Gasteiger charges and AutoDock elements. Then, the energy-minimized 3D conformations of the five nucleotides, 21 phenolic acids, and four diterpenoids of AERL were treated as flexible and prepared by AutoDockTools 1.5, ie, merging nonpolar hydrogens, assigning Gasteiger charges, finding root and aromatic carbons, detecting rotatable bonds, and setting torsions. The grid box dimensions were set to $22.5 \AA \times 30 \AA \times 30 \AA$ using a grid spacing of $0.375 \AA$ for two average structures.

To determine the probable binding conformations, AutoDock 4, a very popular docking program with a high success rate, the energy-minimized 3D conformations of the five nucleotides, 21 phenolic acids, and four diterpenoids of AERL were used to dock into the active sites of the average structure of P-selectin. This allows automated docking of flexible ligands to a rigid receptor with certain flexible residues. The residues within $4 \AA$ of SLeX and PSGL-1 in crystal structures were the residue set of Tyr45, Ser46, Ser47, Arg85, His108, Lys111, Lys112, and His114 and the residue set of Tyr48, Lys84, Arg85, Glu88, Glu92, Tyr94, Ser99, and Glu107, respectively, as well as $\mathrm{Ca}^{2+}$ coordinating residue set of Glu80, Asn82, Asn105, and Asp106. The residues of the active pockets of the average structure should be limited in these residues. Lamarckian genetic algorithm was used to find the appropriate binding positions, orientations, and conformations of the five nucleotides, 21 phenolic acids, and four diterpenoids of AERL in the binding site of the average structure. The global optimization was started with parameters of a population of 100 randomly positioned individuals. The maximum number of energy evaluations was increased to $2.5 \times 10^{7}$ and the maximum number of generations in the Lamarckian genetic algorithm was increased to $2.7 \times 10^{5}$. The Solis and Wets local search was performed with a maximum number of 3,000. During each simulation experiment, 256 runs were carried out for each of the AERL ingredients. The resulting 256 conformations of the five nucleotides, 21 phenolic acids, and four diterpenoids were scored by the lowest binding energy and clustered using a root mean square tolerance of $2.0 \AA$.

\section{Statistical analysis}

Data analysis was performed using an ANOVA test. A $P$-value less than 0.05 was considered as statistically significant.

\section{Results \\ AERL selectively inhibits platelet aggregation in vitro}

The in vitro antiplatelet aggregation assay was performed, and the $\mathrm{IC}_{50}$ values are shown in Figure 1 . The $\mathrm{IC}_{50}$ values of AERL against TH-, AA-, ADP-, and PAF-induced platelet aggregation were $0.12 \mathrm{mg} / \mathrm{mL}, 0.24 \mathrm{mg} / \mathrm{mL}, 1.24 \mathrm{mg} / \mathrm{mL}$, and $1.43 \mathrm{mg} / \mathrm{mL}$, respectively. In respect of the sensitivity to AERL, the $\mathrm{IC}_{50}$ value of AERL against TH-induced platelet aggregation was significantly lower than those of AERL against AA-, ADP-, and PAF-induced platelet aggregation. Therefore, AERL selectively inhibits $\mathrm{TH}$-induced platelet aggregation.

\section{AERL dose-dependently inhibits rats from forming thrombus in vivo}

Thrombus weights were measured in the rat model, and the data are shown in Figure 2. The thrombus weights of the rats orally receiving $25 \mathrm{mg} / \mathrm{kg}$ and $50 \mathrm{mg} / \mathrm{kg}$ of AERL were significantly lower than that of the rats orally receiving NS, while the thrombus weight of the rats orally receiving $5 \mathrm{mg} / \mathrm{kg}$ of AERL was equal to that of the rats orally receiving NS. On the other hand, when the dose increased from $5 \mathrm{mg} / \mathrm{kg}$ to $25 \mathrm{mg} / \mathrm{kg}$ and $50 \mathrm{mg} / \mathrm{kg}$, the thrombus weight gradually decreased. These data demonstrate that AERL can prevent thrombus formation in a dose-dependent manner, and the minimal effective dose is $25 \mathrm{mg} / \mathrm{kg}$.

\section{AERL concentration-dependently inhibits platelets to release $\mathrm{P}$-selectin in vitro}

To determine the effect of AERL on platelets releasing sP-selectin, NS and $3 S$-tetrahydroisoquinoline-3-carboxylic acid (IQCA) (a known P-selectin inhibitor ${ }^{23}$ ) were used as the blank and positive controls, respectively. The concentrations of sP-selectin released from AA-activated platelets treated with NS, IQCA, and AERL were measured, and the results are shown in Figure 3. As can be seen, the levels of $\mathrm{sP}$-selectin from the platelets treated with $0.1 \mathrm{mM}$ of IQCA and $0.1 \mathrm{mg} / \mathrm{mL}$ and $1.0 \mathrm{mg} / \mathrm{mL}$ of AERL were significantly lower than that of sP-selectin from the platelets treated with 


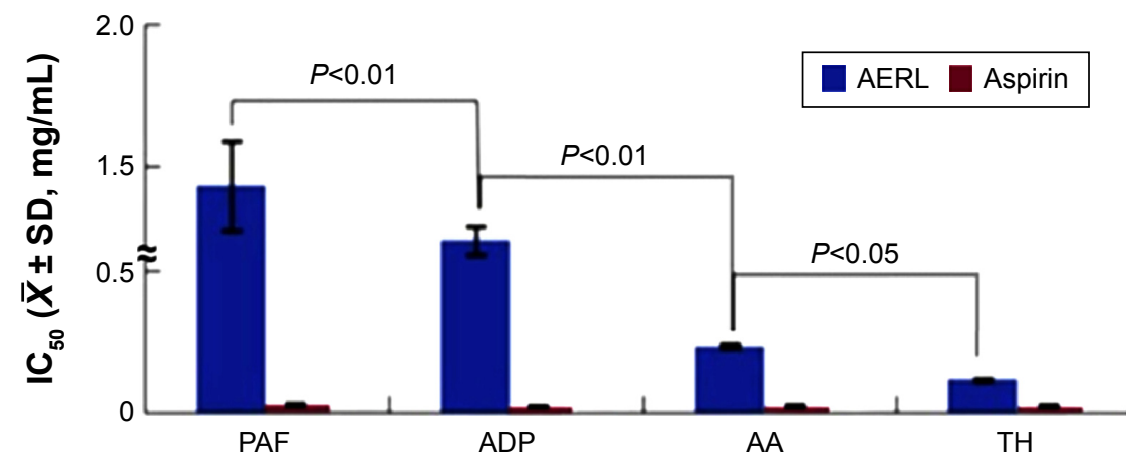

Figure $I \mathrm{IC}_{50} \mathrm{~s}$ of AERL inhibiting platelet aggregation induced by PAF, ADP, AA, and TH.

Notes: Aspirin was the positive control. $n=6$.

Abbreviations: AA, arachidonic acid; ADP, adenosine diphosphate; AERL, aqueous extract of Rabdosia rubescens leaves; PAF, platelet-activating factor; SD, standard deviation; $\mathrm{TH}$, thrombin; $\mathrm{IC}_{50}$, half maximal inhibitory concentration.

NS, while the level of sP-selectin from the platelets treated with $0.01 \mathrm{mg} / \mathrm{mL}$ of AERL was equal to that of sP-selectin from the platelets treated with NS. These data demonstrate that AERL can downregulate platelet SP-selectin release in a concentration-dependent manner.

\section{In water, AERL forms nanoparticles}

To show the nanoimage of the lyophilized solids of AERL in water, a TEM test was performed. Using the standard procedure, the nanofeatures of various concentrations of AERL were defined and are shown in Figure 4A-D and Figure S3. Figure 4A indicates that $1.0 \mathrm{mg} / \mathrm{mL}$ of AERL formed nanoparticles of $4.5-63.6 \mathrm{~nm}$ in diameter. Figure 4B indicates that $0.5 \mathrm{mg} / \mathrm{mL}$ of AERL formed nanoparticles of $32.9-180.8 \mathrm{~nm}$ in diameter. Figure 4C indicates that $0.25 \mathrm{mg} / \mathrm{mL}$ of AERL formed nanoparticles of $38.9-227.8 \mathrm{~nm}$ in diameter. Figure 4D indicates that $0.12 \mathrm{mg} / \mathrm{mL}$ of AERL formed nanoparticles of 45.7-234.3 nm in diameter. These data show that, with the concentration decreases from $1.0 \mathrm{mg} / \mathrm{mL}$ to $0.12 \mathrm{mg} / \mathrm{mL}$, the diameter of the nanoparticles progressively increased.

A
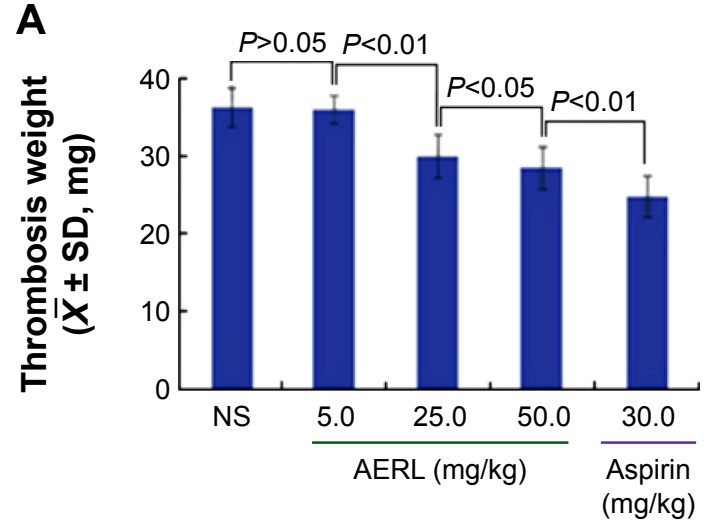

\section{In rat plasma, $A E R L$ forms nanoparticles}

To show the nanoimage of the lyophilized solids of AERL dissolved in rat plasma, an AFM test was performed. Using the standard procedure, the nanofeature of the $0.5 \mathrm{mg} / \mathrm{mL}$ solution of AERL in plasma was defined and is shown in Figure 4E. Figure 4F, the AFM image of plasma alone, indicates that in plasma alone, no interesting nanospecies were formed. Figure 4E indicates that, in rat plasma, $0.5 \mathrm{mg} / \mathrm{mL}$ of AERL formed nanoparticles of 53-159 $\mathrm{nm}$ in diameter. Therefore, in rat plasma, AERL forms nanoparticles.

\section{The docking feature of rosmarinic acid in $P$-selectin's active site}

To address the antithrombotic ingredient of AERL, dockingbased screening was performed. In brief, five nucleotides, 21 phenolic acids, and four diterpenoids of AERL, ${ }^{15}$ of which the HPLC-PDA 3D chromatogram is shown in Figure 5 and Table S1, were docked into the active site of P-selectin. The docking demonstrated that rosmarinic acid had the lowest energy and could be assigned as the antithrombotic

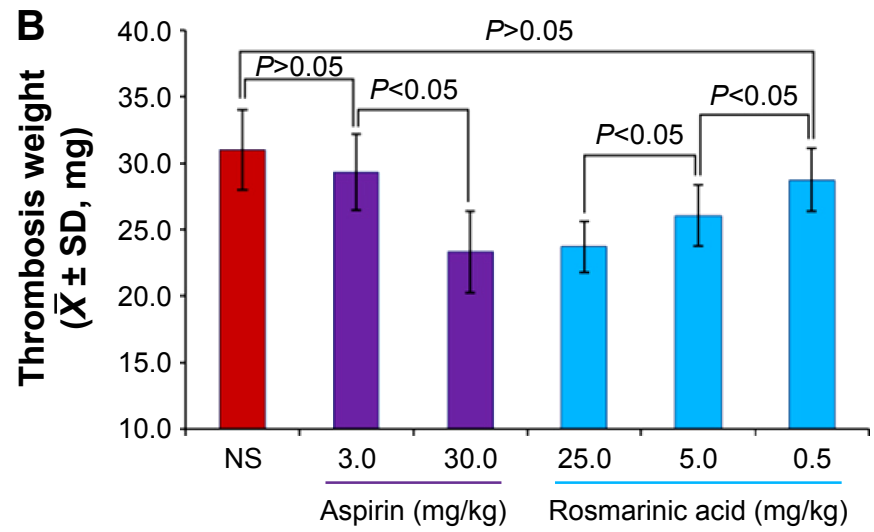

Figure 2 Thrombus weights of rats orally receiving $A E R L$ and rosmarinic acid.

Notes: (A) Thrombus weights of rats orally receiving AERL. (B) Thrombus weights of rats orally receiving rosmarinic acid. Aspirin was the positive control. $\mathrm{n}=10$. Abbreviations: AERL, aqueous extract of Rabdosia rubescens leaves; NS, normal saline; SD, standard deviation. 


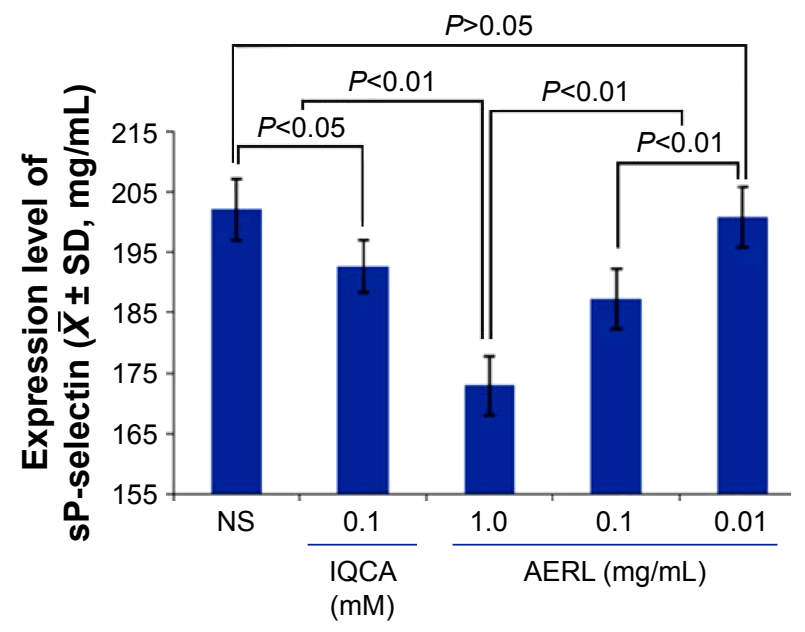

Figure 3 Effect of AERL on the in vitro release of sP-selectin from platelets. Notes: IQCA was the reference compound. $n=4$.

Abbreviations: AERL, aqueous extract of Rabdosia rubescens leaves; IQCA, 3Stetrahydroisoquinoline-3-carboxylic acid; NS, normal saline; SD, standard deviation; sP-selectin, soluble P-selectin.

ingredient of AERL. The docking feature of rosmarinic acid in P-selectin's active site was defined by the interactions of the hydroxyl and carboxyl of rosmarinic acid with the amino acid residues of the active site and is shown in
Figure 5A, in which the $\mathrm{H}$ and $\mathrm{O}$ of 2-OH with $\alpha$-carbonyl of Asp78 (instance, $2.70 \AA$ ) and the side NH of Asn82 (instance, $3.02 \AA$ ) form hydrogen bonds, respectively; the $\mathrm{H}$ and $\mathrm{O}$ of 3-OH with $\alpha$-carbonyl (instance, $3.02 \AA$ ) and $\alpha-\mathrm{NH}$ (instance, $3.01 \AA$ ) of Asp78 form hydrogen bonds, respectively; the $\mathrm{O}$ of carboxylic $\mathrm{OH}$ with the side $\mathrm{NH}_{3}$ of Lys111 (instance, $2.69 \AA$ ) form a hydrogen bond; side $\mathrm{NH}_{3}$ of Lys 113 with $\mathrm{O}$ of $16 \mathrm{OH}$ (instance, $3.01 \AA$ ) and $17 \mathrm{OH}$ (instance, $2.97 \AA$ ) for hydrogen bonds; and the $\mathrm{H}$ of $17-\mathrm{OH}$ with the side carbonyl of Glu92 (instance, $2.70 \AA$ ) form a hydrogen bond. The interactions suggest that rosmarinic acid could be the antithrombotic ingredient of AERL. Thus, rosmarinic acid (Aladdin Company, Shanghai, People's Republic of China) was purchased to perform flow cytometry and antithrombotic assays.

\section{Rosmarinic acid downregulates P-selectin expression}

According to the docking investigation, rosmarinic acid, the main ingredient of AERL, was tested in flow cytometry analysis. ${ }^{24,25}$ The structure is identified by NME spectra, in Figure S1 and Figure S2. Figure 6 shows that, in vitro, $0.1 \mu \mathrm{M}$
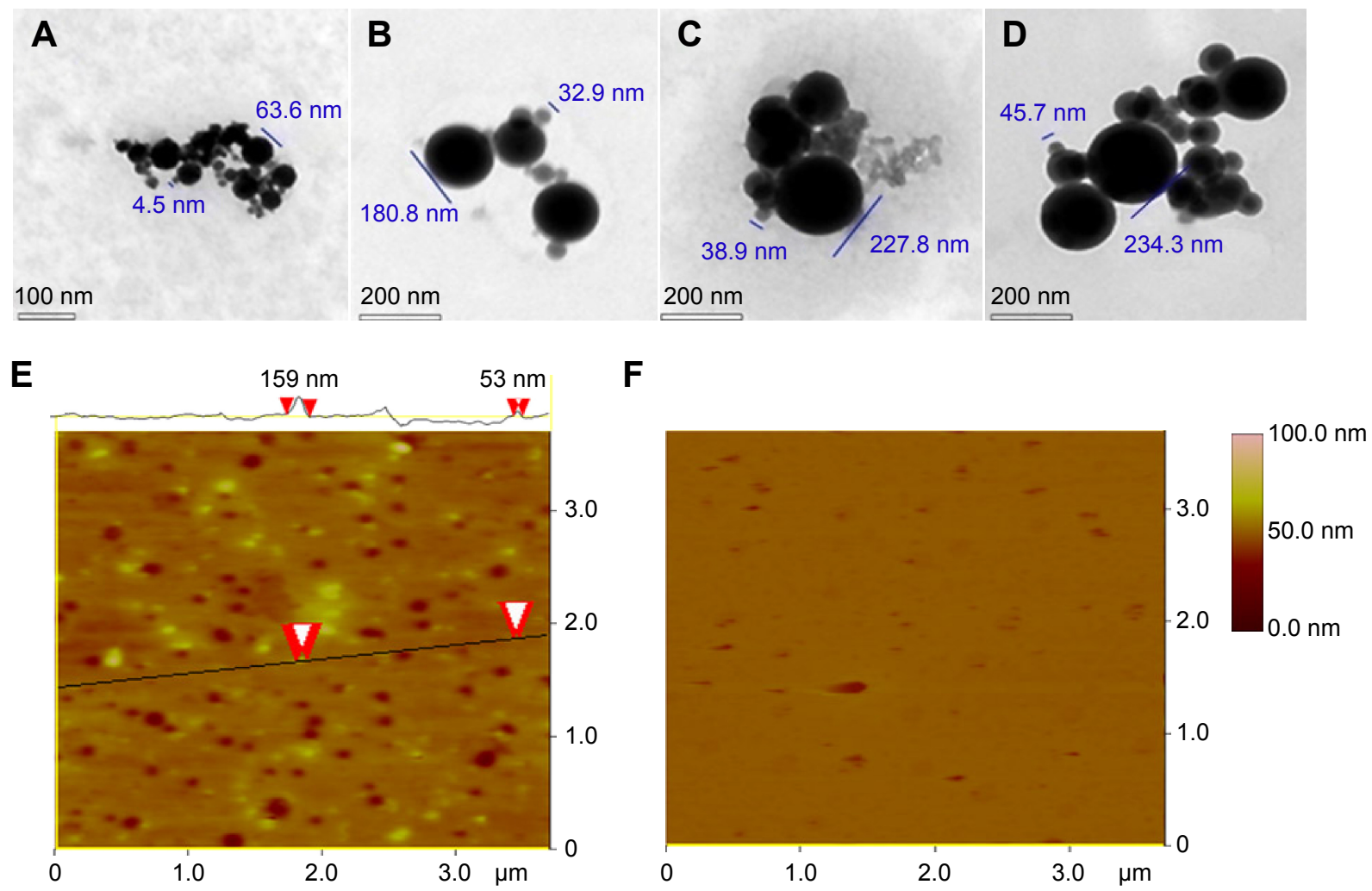

Figure 4 TEM and AFM images showing the nanostructure of the lyophilized solids of AERL in water and rat plasma.

Notes: (A) TEM image of nanoparticles of AERL in water, $4.5-63.6 \mathrm{~nm}$ in diameter (concentration, $1.0 \mathrm{mg} / \mathrm{mL}$ ). (B) TEM image of nanoparticles of AERL in water, 32.9-I80.8 nm in diameter (concentration, $0.5 \mathrm{mg} / \mathrm{mL}$ ). (C) TEM image of nanoparticles of AERL in water, 38.9-227.8 nm in diameter (concentration, $0.25 \mathrm{mg} / \mathrm{mL}$ ). (D) TEM image of nanoparticles of AERL in water, $45.7-234.3 \mathrm{~nm}$ in diameter (concentration, $0.12 \mathrm{mg} / \mathrm{mL}$ ). (E) AFM image of nanoparticles of AERL in rat plasma, $53-159 \mathrm{~nm}$ in diameter (concentration, $0.5 \mathrm{mg} / \mathrm{mL}$ ). Two red arrowheads indicate the diameter of the nanoparticle. (F) AFM image of nanostructure of rat plasma alone.

Abbreviations: AERL, aqueous extract of Rabdosia rubescens leaves; AFM, atomic force microscopy; TEM, transmission electron microscopy. 


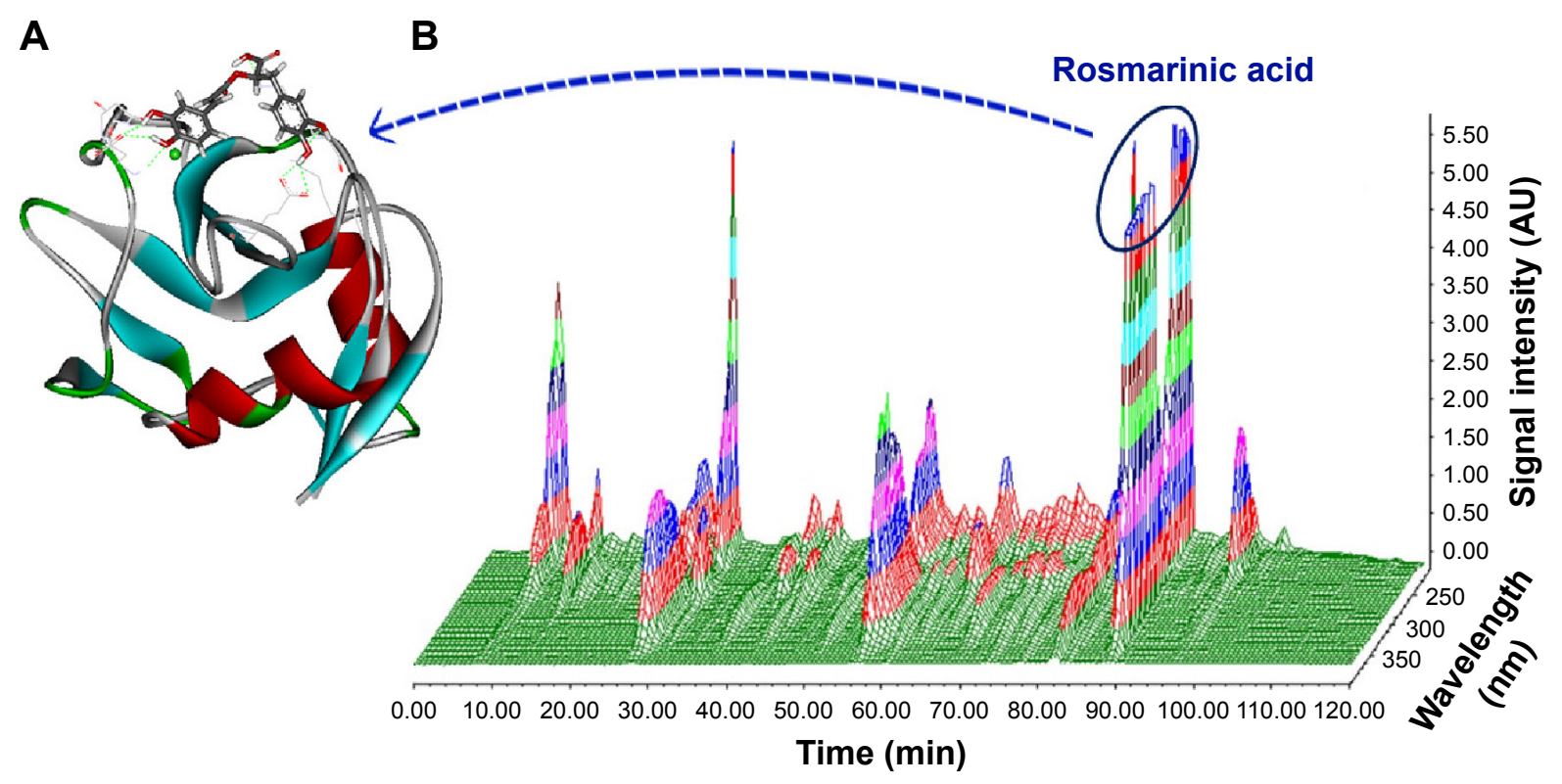

Figure 5 HPLC-PDA 3D chromatogram of AERL and docking feature of rosmarinic acid in the active site of P-selectin.

Notes: (A) Docking feature of rosmarinic acid in the active site of P-selectin. (B) HPLC-PDA 3D chromatogram of AERL (20.34\% in whole extract, calculated from HPLC analysis, $254 \mathrm{~nm}$ ).

Abbreviations: AERL, aqueous extract of Rabdosia rubescens leaves; AU, absorbance unit; HPLC, high-performance liquid chromatography; PDA, photodiode array detector; min, minutes.
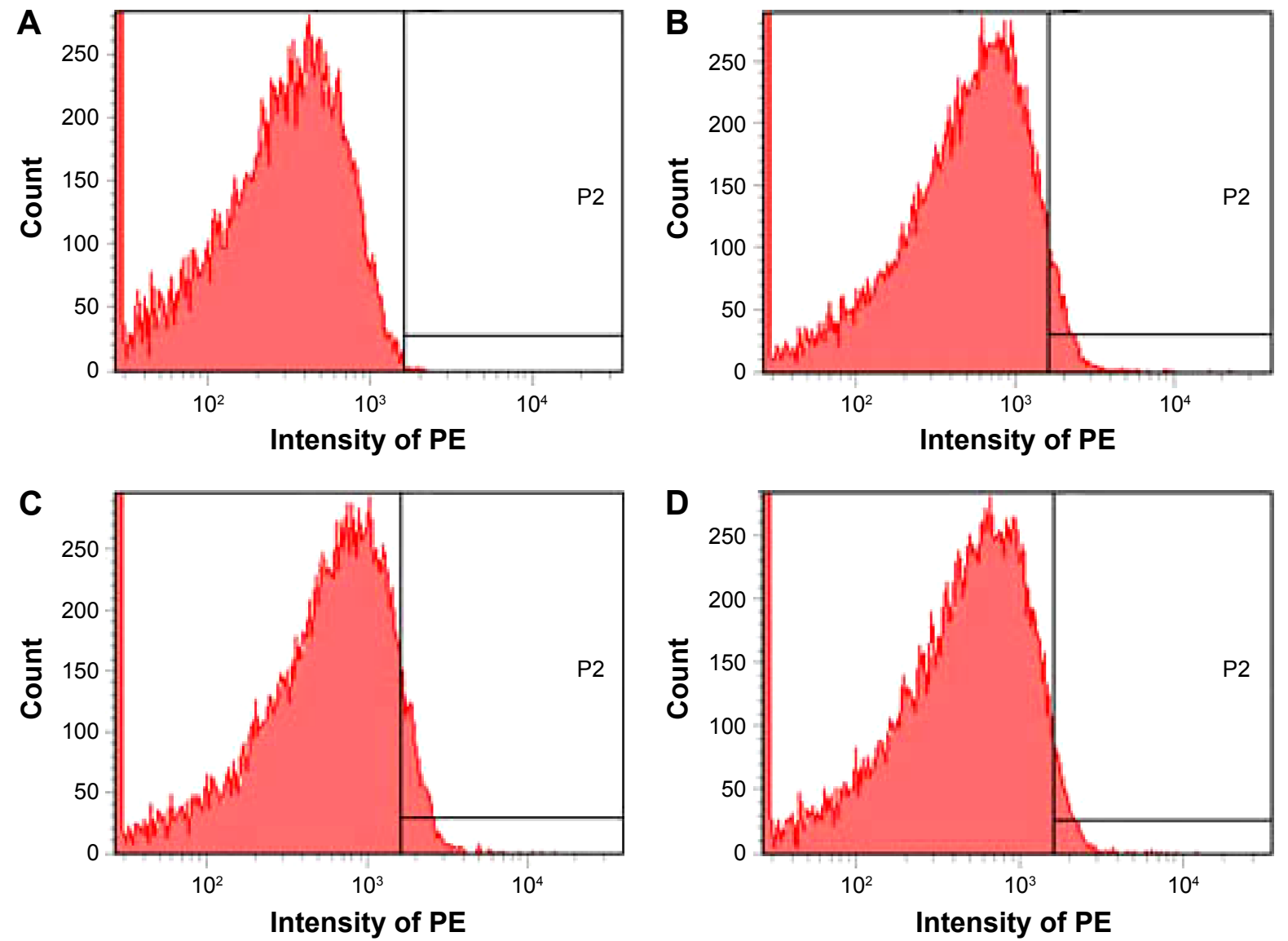

Figure 6 Depression of P-selectin expression by rosmarinic acid.

Notes: (A) Unlabeled platelets (background). (B) PE-anti-CD62P-labeled platelets. (C) PE-anti-CD62P-labeled and AA-activated platelets without rosmarinic acid. (D) PE-anti-CD62P-labeled and AA-activated platelets with I $\mu \mathrm{M}$ of rosmarinic acid. P2, a high fluorescence intensity area in which there is no fluorescence in NS group. Abbreviations: $A A$, arachidonic acid; NS, normal saline; $P E$, phycoerythrin. 
of rosmarinic acid effectively downregulated AA-activated rat platelet $\mathrm{P}$-selectin expression. The fluorescence intensities of unlabeled platelets (background), PE-anti-CD62P-labeled platelets (normal reference), PE-anti-CD62P-labeled and AA-activated platelets without rosmarinic acid (positive control), and PE-anti-CD62P-labeled and AA-activated platelets with $1 \mu \mathrm{M}$ of rosmarinic acid were $17,102,167$, and 105 , respectively. This indicates that the P-selectin level significantly decreased in the presence of $1 \mu \mathrm{M}$ of rosmarinic acid.

\section{Rosmarinic acid inhibits thrombosis in vivo}

According to the flow cytometry analysis, 25, 5, and $0.5 \mathrm{mg} / \mathrm{kg}$ of rosmarinic acid were tested in the in vivo antithrombotic assay, and the data are shown in Figure 2B. The thrombus weights of the rats orally receiving 25 and $5 \mathrm{mg} / \mathrm{kg}$ of rosmarinic acid were significantly lower than that of the rats orally receiving NS, while the thrombus weight of the rats orally receiving $0.5 \mathrm{mg} / \mathrm{kg}$ of rosmarinic acid was equal to that of the rats orally receiving NS. On the other hand, when the dose increased from $0.5 \mathrm{mg} / \mathrm{kg}$ to $5 \mathrm{mg} / \mathrm{kg}$ or $25 \mathrm{mg} / \mathrm{kg}$, the thrombus weight dose-dependently decreased. Thus, rosmarinic acid has the capability of preventing thrombus formation in rats, with a minimal effective dose of $5 \mathrm{mg} / \mathrm{kg}$.

\section{Discussion}

Using the preparation procedure described in the "Materials and methods" section, AERL was obtained in a good yield and had good solubility. Besides, this aqueous extract gave the same chromatogram (Figure 5B) of HPLC-PDA previously reported. ${ }^{15}$ The yield, solubility, and composition of the extract demonstrate that this procedure is suitable for preparing AERL. The $\mathrm{IC}_{50}$ values in Figure 1 not only indicate AERL can effectively inhibit platelet aggregation in vitro, but also show that the potency of AERL inhibiting platelet aggregation induced by TH was twofold, tenfold, and 12-fold higher than that of AERL inhibiting platelet aggregation induced by AA, ADP, and PAF, respectively, and that AERL therefore selectively inhibits $\mathrm{TH}$-induced platelet aggregation.

Figure 2A demonstrates the effective oral dose of AERL inhibiting the in vivo thrombosis was $25 \mathrm{mg} / \mathrm{kg}(6.3 \mathrm{mg}$ per rat). Taking the $\mathrm{IC}_{50}$ values of AERL against platelet aggregation into account, the effective oral dose of $25 \mathrm{mg} / \mathrm{kg}$ supports an interpretation that oral AERL could be sufficiently absorbed in vivo. Since a $250 \mathrm{~g}$ rat maximally has $16 \mathrm{~mL}$ of blood, at a $25 \mathrm{mg} / \mathrm{kg}$ dose, the blood concentration should at least reach $6.3 \mathrm{mg} / 16 \mathrm{~mL}(0.4 \mathrm{mg} / \mathrm{mL})$, which is 3.3-, 1.7-, 0.3-, or 0.3-fold of $0.12 \mathrm{mg} / \mathrm{mL}, 0.24 \mathrm{mg} / \mathrm{mL}$, $1.24 \mathrm{mg} / \mathrm{mL}$, or $1.43 \mathrm{mg} / \mathrm{mL}$ (the $\mathrm{IC}_{50}$ s mentioned above), respectively. This correlation between $\mathrm{IC}_{50}$ and effective dose indicates that $\mathrm{TH}$ and AA could be mainly responsible for the in vivo antithrombotic action, and implies that only a few of the ingredients possess in vitro antiplatelet aggregation and in vivo antithrombotic actions.

As a glycoprotein, P-selectin is normally stored in platelet $\alpha$-granules. Upon activation, $\mathrm{P}$-selectin mobilizes to the surface membrane of the activated platelets, is shed from the platelet surface to form $\mathrm{sP}$-selectin, and is released into the bloodstream. ${ }^{26-29}$ The increase of circulation concentration of sP-selectin plays a core role in thrombosis, and inhibition of sP-selectin production has been considered one of the principal mechanisms of antithrombotic agents. Therefore, Figure 3 depicts concentration dependence of AERL inhibiting AA-activated platelets from releasing sP-selectin and discloses a possible mechanism of action of AERL offering in vitro antiplatelet aggregation and in vivo antithrombotic action.

The TEM nanoimages of Figure 4 indicate that AERL concentration-dependently forms nanoparticles. The nanoparticles formed by $1.0 \mathrm{mg} / \mathrm{mL}$ of AERL had the smallest diameter range (4.5-63.6 $\mathrm{nm}$ ) and the maximum blood concentration of the rats receiving $50 \mathrm{mg} / \mathrm{kg}$ of AERL was $\sim 1.0 \mathrm{mg} / \mathrm{mL}$. The AFM nanoimages of rat plasma alone (Figure $4 \mathrm{~F}$ ) indicate no interesting nanospecies, while Figure 4E indicates that, in rat plasma, $0.5 \mathrm{mg} / \mathrm{mL}$ of AERL formed nanoparticles of 53-159 $\mathrm{nm}$ in diameter, and the diameter of most nanoparticles was less than $100 \mathrm{~nm}$. It is accepted that the particles with a diameter lower than $100 \mathrm{~nm}$ cannot be trapped by macrophages, ${ }^{30}$ and it is understandable that $50 \mathrm{mg} / \mathrm{kg}$ of AERL has desirable in vivo antithrombotic activity.

Through docking of five nucleotides, 21 phenolic acids, and four diterpenoids (Figure 5B) into the active site of $\mathrm{P}$-selectin, rosmarinic acid was proved to be the antithrombotic ingredient of AERL. Figure 5A depicts the docking feature of rosmarinic acid in the active site, defines the hydrogen bonds between the hydroxyl and carboxyl of rosmarinic acid with the principle amino acid residues of the active site of P-selectin, and predicts the possibility of rosmarinic acid being the antithrombotic ingredient of AERL.

The flow cytometry analysis depicted in Figure 6 indicated that $0.1 \mu \mathrm{M}$ of rosmarinic acid could effectively downregulate AA-activated rat platelets to express sPselectin. This in vitro data support the docking-based prediction that rosmarinic acid would be one of the antithrombotic ingredients of AERL. Figure $2 \mathrm{~B}$ exhibits the dose dependence 
of rosmarinic acid in blocking thrombosis, suggesting that the in vivo data also support a prediction that rosmarinic acid is one of the antithrombotic ingredients of AERL.

\section{Conclusion}

AERL concentration-dependently inhibits in vitro platelet aggregation induced by $\mathrm{TH}, \mathrm{AA}, \mathrm{ADP}$, and PAF and selectively inhibits in vitro platelet aggregation induced by TH. In a rat model, oral AERL dose-dependently inhibited thrombosis. Both the in vitro antiplatelet aggregation and the in vivo antithrombotic action were the result of AERL inhibiting AA-activated platelets from releasing sP-selectin. In water, AERL concentration-dependently forms nanoparticles. The nanoparticles formed in $1.0 \mathrm{mg} / \mathrm{mL}$ of aqueous AERL had a small size and benefited both the in vitro adhesion and the in vivo delivery. The docking-based screening of the five nucleotides, 21 phenolic acids, and four diterpenoids identified by HPLC-PDA/(-)ESI-MS/MS analysis predicted that rosmarinic acid was the antithrombotic ingredient of AERL, which was confirmed by flow cytometry assay and rat model-based in vivo antithrombotic assay.

\section{Acknowledgments}

This work was supported by the National Natural Science Foundation of China (81273379, 81202412, and 81373265), 863 program (2015AA020902), Beijing Municipal Science and Technology Commission (Z141100002114049, TJSHG201310025008), Importation and Development of High-Caliber Talents Project of Beijing Municipal Institutions (CIT\&TCD201304191), Scientific Research Project of Beijing Municipal Commission of Education (KM201310025006), Beijing NOVA Programme xx2013039, and Beijing Natural Science Foundation (7132032).

\section{Disclosure}

The authors report no conflicts of interest in this work.

\section{References}

1. Bektas N, Arslan R, Goger F, Kirimer N, Ozturk Y. Investigation for anti-inflammatory and anti-thrombotic activities of methanol extract of Capparis ovata buds and fruits. J Ethnopharmacol. 2012;142(1):48-52.

2. Azevedo AP, Farias JC, Costa GC, et al. Anti-thrombotic effect of chronic oral treatment with Orbignya phalerata Mart. J Ethnopharmacol. 2007; 111(1):155-159.

3. Chang GT, Kang SK, Kim JH, Chung KH, Chang YC, Kim CH. Inhibitory effect of the Korean herbal medicine, Dae-Jo-Whan, on plateletactivating factor-induced platelet aggregation. J Ethnopharmacol. 2005; 102(3):430-439.

4. Kamruzzaman SM, Endale M, Oh WJ, et al. Inhibitory effects of Bulnesia sarmienti aqueous extract on agonist-induced platelet activation and thrombus formation involves mitogen-activated protein kinases. J Ethnopharmacol. 2010;130(3):614-620.
5. Yan Y, O W, Zhao X, et al. Effect of essential oil of Syringa pinnatifolia Hemsl. var. alashanensis on ischemia of myocardium, hypoxia and platelet aggregation. J Ethnopharmacol. 2010;131(2):248-255.

6. Amrani S, Harnafi H, Gadi D, et al. Vasorelaxant and anti-platelet aggregation effects of aqueous Ocimum basilicum extract. JEthnopharmacol. 2009;125(1):157-162.

7. Du Y, Liu P, Yuan Z, et al. Simultaneous qualitative and quantitative analysis of 28 components in Isodon rubescens by HPLC-ESI-MS/MS. J Sep Sci. 2010;33(4-5):545-557.

8. Lu Y, Sun C, Liu R, Pan Y. Effective two-dimensional counter-current chromatographic method for simultaneous isolation and purification of oridonin and ponicidin from the crude extract of Rabdosia rubescens. J Chromatogr A. 2007;1146(1):125-130.

9. Cheng Y, Qiu F, Huang J, Tashiro S, Onodera S, Ikejima T. Apoptosissuppressing and autophagy-promoting effects of calpain on oridonininduced L929 cell death. Arch Biochem Biophys. 2008;475(2): $148-155$.

10. Hsieh TC, Wijeratne EK, Liang JY, Gunatilaka AL, Wu JM. Differential control of growth, cell cycle progression, and expression of NF-kappaB in human breast cancer cells MCF-7, MCF-10A, and MDA-MB-231 by ponicidin and oridonin, diterpenoids from the chinese herb Rabdosia rubescens. Biochem Biophys Res Commun. 2005; 337(1):224-231.

11. Lou $\mathrm{H}$, Zhang $\mathrm{X}$, Gao L, et al. In vitro and in vivo antitumor activity of oridonin nanosuspension. Int J Pharm. 2009;379(1):181-186.

12. Kang N, Zhang JH, Qiu F, Tashiro S, Onodera S, Ikejima T. Inhibition of EGFR signaling augments oridonin-induced apoptosis in human laryngeal cancer cells via enhancing oxidative stress coincident with activation of both the intrinsic and extrinsic apoptotic pathways. Cancer Lett. 2010;294(2):147-158.

13. Zhang Y, Wu Y, Wu D, Tashiro S, Onodera S, Ikejima T. NF-kappab facilitates oridonin-induced apoptosis and autophagy in HT1080 cells through a p53-mediated pathway. Arch Biochem Biophys. 2009; 489(1-2):25-33.

14. Zou J, Pan L, Li Q, et al. Rubesanolides A and B: diterpenoids from Isodon rubescens. Org Lett. 2011;13(6):1406-1409.

15. Tang J, Zhao M, Wang Y, et al. One single HPLC-PDA/(-)ESI-MS/MS analysis to simultaneously determine 30 components of the aqueous extract of Rabdosia rubescens. J Chromatogr B Analyt Technol Biomed Life Sci. 2011;879(26):2783-2793.

16. Jin S, Wang $\mathrm{Y}$, Zhu H, et al. Nanosized aspirin-Arg-Gly-Asp-Val: delivery of aspirin to thrombus by the target carrier Arg-Gly-Asp-Val tetrapeptide. ACS Nano. 2013;7(9):7664-7673.

17. Ferroni P, Martini F, Riondino S, et al. Soluble P-selectin as a marker of in vivo platelet activation. Clin Chim Acta. 2009;399(1-2): 88-91.

18. Scazziota A, Altman R, Rouvier J, et al. Abciximab treatment in vitro after aspirin treatment in vivo has additive effects on platelet aggregation, ATP release, and P-selectin expression. Thromb Res. 2000;100(6):479-488.

19. Kariyazono H, Nakamura K, Shinkawa T, Yamaguchi T, Sakata R, Yamada K. Inhibition of platelet aggregation and the release of P-selectin from platelets by cilostazol. Thromb Res. 2001;101(6):445-453.

20. Sanz MJ, Cortijo J, Morcillo EJ. PDE4 inhibitors as new anti-inflammatory drugs: effects on cell trafficking and cell adhesion molecules expression. Pharmacol Ther. 2005;106(3):269-297.

21. Wang L, Chen WZ, Wu MP. Apolipoprotein A-I inhibits chemotaxis, adhesion, activation of THP-1 cells and improves the plasma HDL inflammatory index. Cytokine. 2010;49(2):194-200.

22. Nyska A, Moomaw CR, Ezov N, et al. Ocular expression of vascular cell adhesion molecule (VCAM-1) in 2-butoxyethanol-induced hemolysis and thrombosis in female rats. Exp Toxicol Pathol. 2003;55(4):231-236.

23. Chen M, Geng JG. Inhibition of protein tyrosine phosphatases suppresses P-selectin exocytosis in activated human platelets. Biochem Biophys Res Commun. 2001;286(3):609-615.

24. Yang $\mathrm{G}, \mathrm{Zhu} \mathrm{H}, \mathrm{Zhao} \mathrm{M}$, et al. The application of tetrahydroisoquinoline3-carbonyl-TARGD(F)F as an anti-thrombotic agent having dual mechanisms of action. Mol Biosyst. 2012;8(10):2672-2679. 
25. Huang G, Zhou Z, Srinivasan R, et al. Affinity manipulation of surfaceconjugated RGD peptide to modulate binding of liposomes to activated platelets. Biomaterials. 2008;29(11):1676-1685.

26. Musumeci D, Montesarchio D. Polyvalent nucleic acid aptamers and modulation of their activity: a focus on the thrombin binding aptamer. Pharmacol Ther. 2012;136:202-215.

27. Wu J, Wang Y, Wang Y, et al. Cu(2+)-RGDFRGDS: exploring the mechanism and high efficacy of the nanoparticle in antithrombotic therapy. Int J Nanomedicine. 2015;10:2925-2938.

28. Samuel SP, Santos-Martinez MJ, Medina C, et al. CdTe quantum dots induce activation of human platelets: implications for nanoparticle hemocompatibility. Int J Nanomedicine. 2015;10:2723-2734.
29. Santos-Martinez MJ, Inkielewicz-Stepniak I, Medina C, et al. The use of quartz crystal microbalance with dissipation (QCM-D) for studying nanoparticle-induced platelet aggregation. Int $J$ Nanomedicine. 2012;7:243-255.

30. Fujita Y, Mie M, Kobatake E. Construction of nanoscale protein particle using temperature-sensitive elastin-like peptide and polyaspartic acid chain. Biomaterials. 2009;30(20):3450-3457. 


\section{Supplementary materials}

Identification of 30 peaks by (-)ESI-MS/MS spectrum of aqueous extract of

\section{$R$. rubescens leaves}

Nuclear magnetic resonance spectra of rosmarinic acid

Faraday-Tyndall effect: scattering of laser beam by aqueous extract of Rabdosia rubescens leaves

In aqueous extract of $R$. rubescens leaves (AERL), a series of surfactant-like components, such as monocaffeoyltartaric acid, fertaric acid, chlorogenic acid, chlorogenic acid-p-hydroxycinnamic acid-tartaric acid, rosmarinic acid-danshensu-tartaric acid, and caffeic acid-danshensuquinic acid-tartaric acid-malonic acid, are involved. These surfactant-like components can help the components without desirable water solubility, such as rosmarinic acid and diterpenoids, to enter into water. On the other hand, the coexistence of these surfactant-like components and the components without desirable water solubility would form nanosolution. Thus, the laser (650 nm)-induced Faraday-Tyndall effect of AERL was tested and is shown in Figure S3. As can be seen, when $0.5 \mathrm{mg} / \mathrm{mL}$ or $15 \mathrm{mg} / \mathrm{mL}$ of AERL was irradiated with a $650 \mathrm{~nm}$ laser beam, the Faraday-Tyndall effect clearly occurred. In addition, the zeta potential and particle size of AERL were determined on a Malvern Zetasizer (Nano ZS90; Malvern Instruments, Malvern, UK) with the DTS (Nano) program and are shown in Figure S3D and E.

Table SI Thirty peaks and (-)ESI-MS/MS spectrum assigned structures

\begin{tabular}{|c|c|c|c|c|c|}
\hline Peak & $t_{R}(\min )$ & MS $^{2}$ data & MS & $\lambda_{\max }(\mathrm{nm})$ & Assigned ingredient \\
\hline $\mathrm{I}$ & 10.1 & 346,211 & 346.0524 & 258 & AMP \\
\hline 2 & 10.6 & 362,211 & 362.0459 & 258 & GMP \\
\hline 3 & 12.2 & 344,150 & 344.0376 & 255 & cGMP \\
\hline 4 & 16.1 & 328,134 & 328.0428 & 258 & cAMP \\
\hline 5 & 17.5 & 282,150 & 282.0831 & 256 & Guanosine \\
\hline 6 & 24.1 & $311,179,149,135,113$ & 311.0381 & 327,218 & Monocaffeoyltartaric acid \\
\hline 7 & 26.2 & $197,179,135$ & 197.0439 & 280 & Danshensu \\
\hline 8 & 29.3 & $491,329,293,197,179,135$ & 491.0799 & 315 & Caffeoyl-dihydroxyphenyllactoyltartaric acid \\
\hline 9 & 32.5 & $649,469,353,295,163,149$ & 649.1392 & 273 & $\begin{array}{l}\text { Chlorogenic acid-p-hydroxycinnamic } \\
\text { acid-tartaric acid }\end{array}$ \\
\hline 10 & 37.6 & $325,193,131,113$ & 325.0538 & 270 & Fertaric acid \\
\hline 11 & 45.5 & $353,191,179,173,161,155,135$ & 353.0845 & 327,291 & Chlorogenic acid \\
\hline 12 & 50.7 & $295,179,133,115$ & 295.0426 & 327 & Caffeoylmalic acid \\
\hline 13 & 52.1 & $473,311,293,179$ & 473.0752 & 149,113 & Dicaffeoyltartaric acid \\
\hline 14 & 53.8 & $671,539,359,179,149$ & 671.1232 & 274,328 & Rosmarinic acid-danshensu-tartaric acid \\
\hline 15 & 57.1 & $57 I, 527,483,439,329,285,24 I, I 97$ & 571.11111 & 276,325 & Yuannaneic acid E \\
\hline 16 & 60.5 & $537,493,357,313,295,197,179,161,135$ & 537.1030 & 276,330 & Lithospermic acid \\
\hline 17 & 62.9 & 179,135 & 179.0344 & 328 & Caffeic acid \\
\hline 18 & 64.5 & $457,311,295,293,277,179,163,149$ & 457.0787 & 315,291 & $\begin{array}{l}\text { Monocaffeoyl-p-hydroxycinnamoyl-tartaric } \\
\text { acid }\end{array}$ \\
\hline 19 & 65.6 & $539,521,495,477,359,341,315,297,197$ & 539.1026 & 277 & Hydrolithospermic acid \\
\hline 20 & 67.0 & $527,483,439,329,303,285,24 I, 197$ & 527.1003 & 283,330 & Danshensu-acetyl \\
\hline 21 & 69.5 & $487,325,307,293,219,193,179,135$ & 487.0911 & 277,327 & Caffeoyl feruloyl \\
\hline 22 & 69.9 & $\begin{array}{l}75 \mathrm{I}, 707,663,533,509,465,329,3 \mathrm{II}, \\
285,267,197\end{array}$ & 751.1341 & 277,320 & $\begin{array}{l}\text { Caffeic acid-danshensu-quinic acid-tartaric } \\
\text { acid-malonic acid }\end{array}$ \\
\hline 23 & 71.4 & $735,717,519,539,339,197,179$ & 735.1573 & 268,336 & Hydrasalvianolic acid B \\
\hline 24 & 75.5 & $719,539,519,475,359,197$ & 719.1615 & 277,330 & Bi-danshensu rosmarinic acid \\
\hline 25 & 78.0 & $717,519,475,359,339,197$ & 717.1493 & $256,283,346$ & Salvianolic acid B \\
\hline 26 & 85.0 & $359,197,179,161,135$ & 359.0778 & 289,331 & $\begin{array}{l}\text { Rosmarinic acid ( } 20.34 \% \text { in whole extract, } \\
\text { calculated from HPLC analysis, } 254 \mathrm{~nm})\end{array}$ \\
\hline 27 & 95.5 & $363,345,327,309,297,28 I$ & 363.1797 & 240 & Oridonin \\
\hline 28 & 98.4 & $361,343,325,299,27 \mathrm{I}$ & 361.1630 & 280 & Ponicidin \\
\hline 29 & 99.2 & $407,347,329,311$ & 407.2069 & 236 & Lasiokaurinol \\
\hline 30 & 115.2 & $347,329,311,299,285$ & 347.1855 & 238 & Effusanin A \\
\hline
\end{tabular}

Abbreviations: HPLC, high-performance liquid chromatography; min, minutes; (-)ESI-MS/MS, (-)electrospray ionization-tandem mass spectrometry; $t_{R}$, time of retention; $\mathrm{MS}^{2}$, tandem mass spectrometry; MS, mass spectrometry. 
A

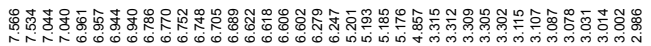

ن

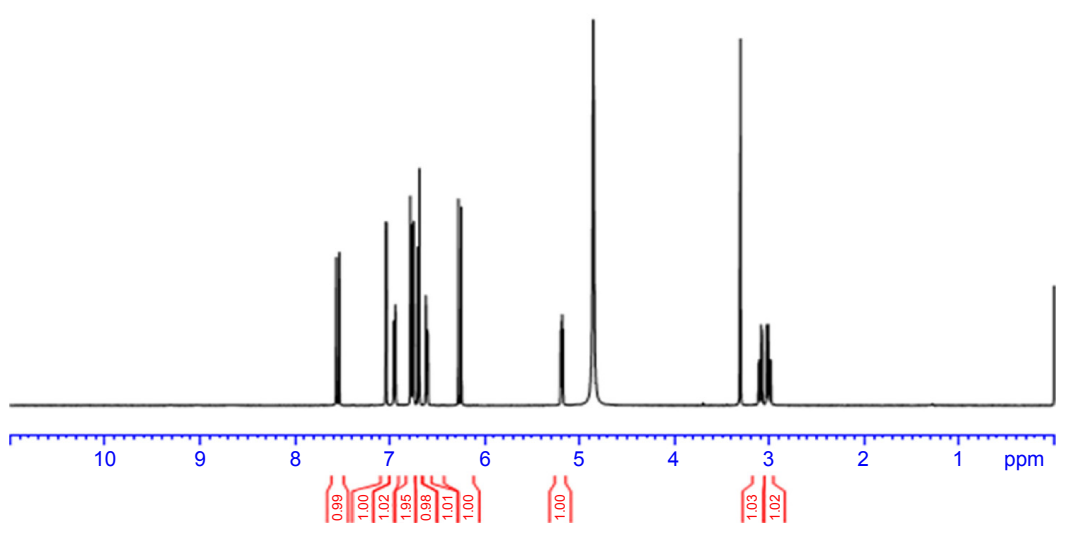

B<smiles>CC(=Cc1ccc(O)c(O)c1)C(=O)O[C@@H](Cc1ccc(O)c(O)c1)C(=O)O</smiles>

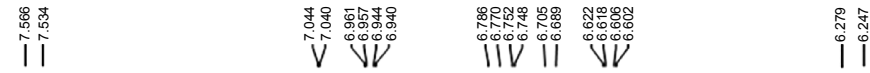
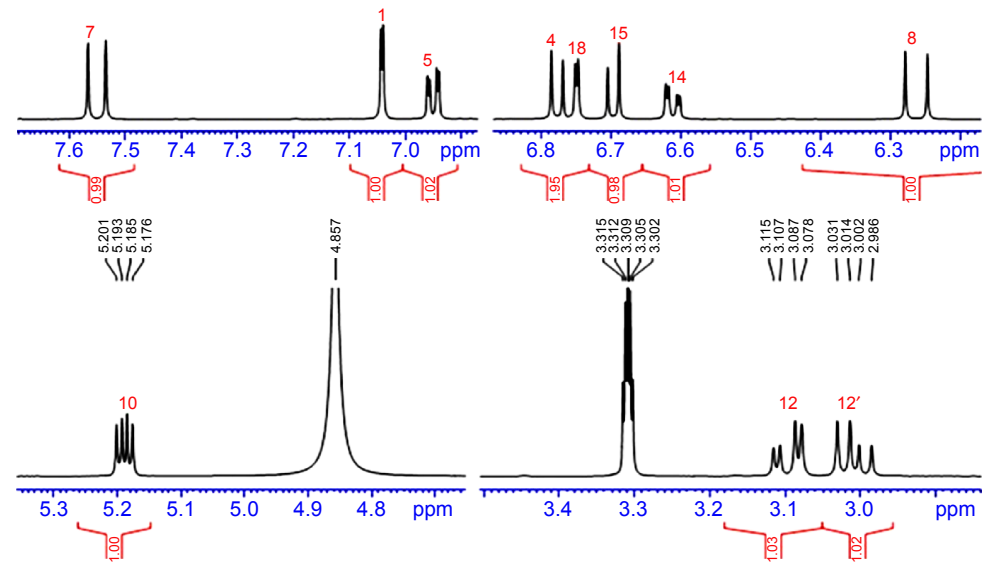

Figure SI 'H NMR of rosmarinic acid.

Notes: (A) 'H NMR of rosmarinic acid; (B) enlarged image of ' $\mathrm{H}$ NMR of rosmarinic acid. 'H NMR (500 MHz, MeOD): $\delta / P p m=7.54$ (d, J=I5.5 Hz, IH), 7.03 (d, J=2 Hz, IH), $6.94(\mathrm{dd}, J=8.0 \mathrm{~Hz}, 2.0 \mathrm{~Hz}, \mathrm{IH}), 6.77(\mathrm{~d}, J=8.0 \mathrm{~Hz}, \mathrm{IH}), 6.74(\mathrm{~d}, J=2.0 \mathrm{~Hz}, \mathrm{IH}), 6.69(\mathrm{~d}, J=8.5 \mathrm{~Hz}, \mathrm{IH}), 6.60(\mathrm{dd}, J=8.0 \mathrm{~Hz}, 2.0 \mathrm{~Hz}, \mathrm{IH}), 6.26(\mathrm{~d}, J=I 5.5 \mathrm{~Hz}, \mathrm{IH}), 5.18(\mathrm{~d}, J=8.5$ $\mathrm{Hz}, 4.5 \mathrm{~Hz}, \mathrm{IH}), 3.09$ (dd, J=I4.5 Hz, $4.5 \mathrm{~Hz}, \mathrm{IH}), 3.00$ (dd, J=I4.5 Hz, $8.5 \mathrm{~Hz}, \mathrm{IH}$ ).

Abbreviations: NMR, nuclear magnetic resonace; $\mathrm{H}$, hydrogen. 


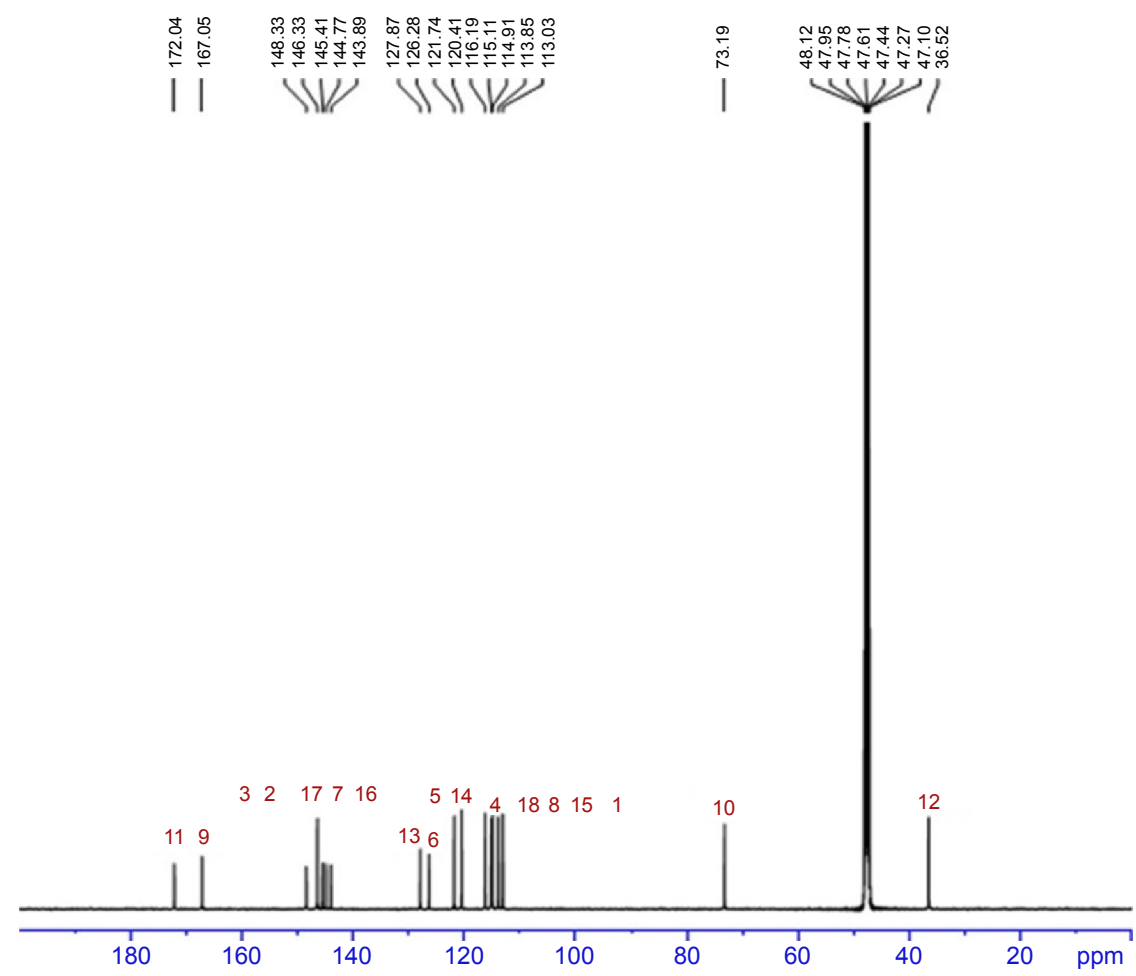

Figure S2 ${ }^{13} \mathrm{C}$ NMR of rosmarinic acid.

Notes: ${ }^{13}$ C NMR (I25 MHz, MeOD): $\delta /$ ppm = I $72.04\left(C_{11}\right)$, I $67.05\left(C_{9}\right)$, I $148.33\left(C_{3}\right), 146.33\left(C_{2}\right), 145.4$ I $\left(C_{17}\right), 144.77\left(C_{7}\right), 143.89\left(C_{16}\right), 127.87\left(C_{13}\right), 126.28\left(C_{6}\right), 121.74\left(C_{5}\right)$, $120.41\left(C_{14}\right)$, II6.19 $\left(C_{4}\right)$, II5.1I $\left(C_{18}\right), 114.91\left(C_{8}\right), 113.85\left(C_{15}\right), 113.03\left(C_{1}\right), 73.19\left(C_{10}\right), 36.52\left(C_{12}\right)$.

Abbreviations: NMR, nuclear magnetic resonace; $C$, carbon. 


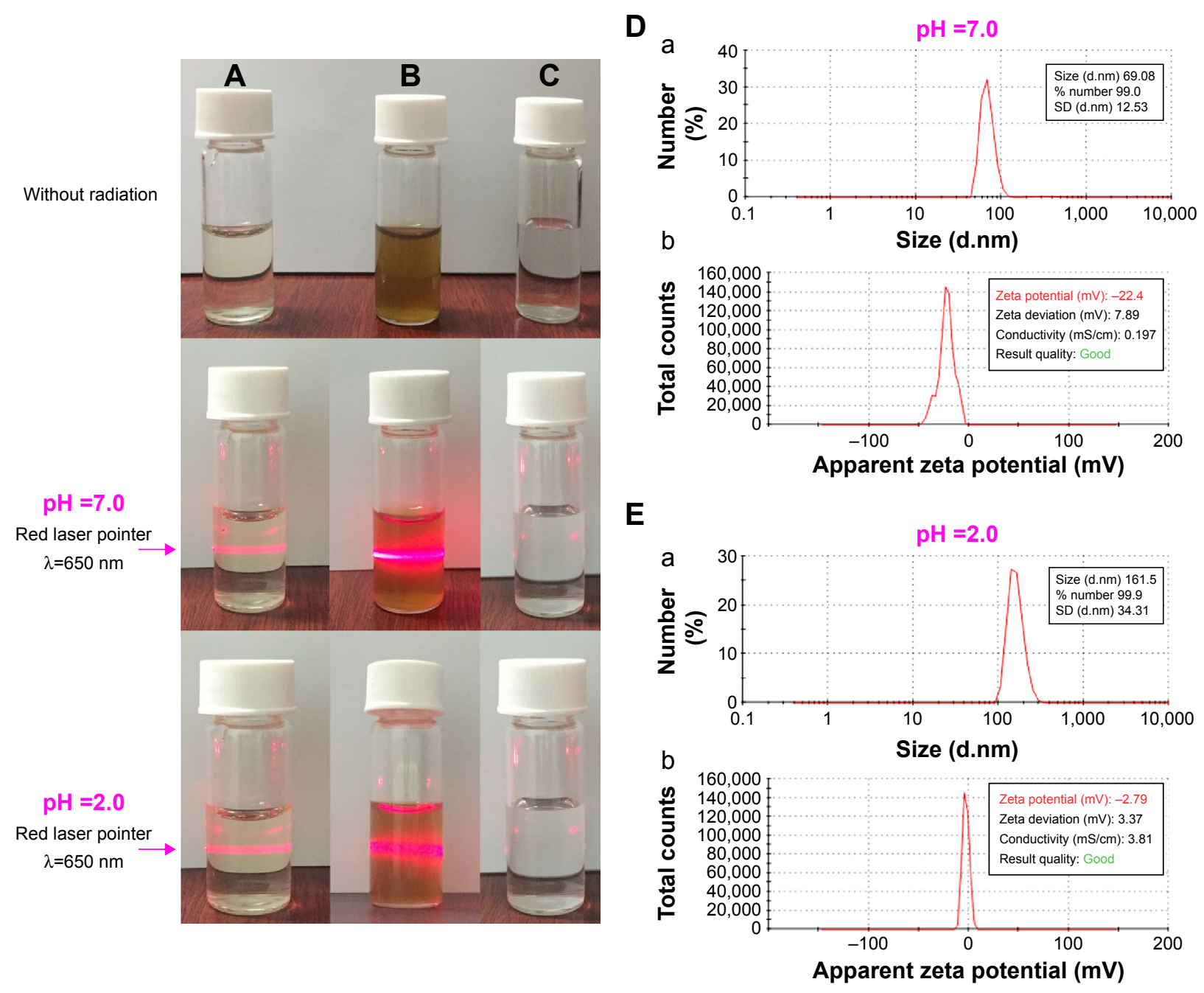

Figure S3 Faraday-Tyndall effect, zeta potential, and size of AERL in $\mathrm{pH} 7.0$ and $\mathrm{pH} 2.0$ water.

Notes: (A) $0.5 \mathrm{mg} / \mathrm{mL}$ of AERL. (B) $15 \mathrm{mg} / \mathrm{mL}$ of AERL. (C) Distilled water. (D) Size (a) and zeta potential (b) of AERL in pH $7.0 \mathrm{water}(0.5 \mathrm{mg} / \mathrm{mL}$ ). (E) Size (a) and zeta potential (b) of AERL in $\mathrm{pH} 2.0$ water $(0.5 \mathrm{mg} / \mathrm{mL})$.

Abbreviations: AERL, aqueous extract of Rabdosia rubescens leaves; SD, standard deviation.

\section{Publish your work in this journal}

The International Journal of Nanomedicine is an international, peerreviewed journal focusing on the application of nanotechnology in diagnostics, therapeutics, and drug delivery systems throughout the biomedical field. This journal is indexed on PubMed Central, MedLine, CAS, SciSearch $\AA$, Current Contents $₫ /$ Clinical Medicine,
Journal Citation Reports/Science Edition, EMBase, Scopus and the Elsevier Bibliographic databases. The manuscript management system is completely online and includes a very quick and fair peer-review system, which is all easy to use. Visit http://www.dovepress.com/ testimonials.php to read real quotes from published authors. 